\title{
Discutindo a aprendizagem sob a perspectiva da teoria ator-rede
}

\section{Discussing learning under actor-network theory perspective}

\author{
Maria de Fátima Aranha de Queiroz e Melo ${ }^{1}$
}

\begin{abstract}
RESUMO
Neste trabalho, discutimos as aprendizagens como um fenômeno dinâmico e multifacetado, produto de uma série de condições que emergem numa causalidade em redes, tomando o corpo enquanto uma instância mediadora que se afeta como um todo nas interações com o mundo. Apoiamo-nos no conceito de tradução defendido pela Teoria Ator-Rede, buscando seus desdobramentos no campo da Psicologia para entender a construção das identidades como apostas sempre provisórias das mesclas de materialidade e socialidade que vão se processando ao longo das biografias dos humanos. Valemo-nos dos princípios Stengers-Despret, atualizados por Latour, apontando para uma epistemologia política alternativa ao fazer uma reflexão sobre o ensinar, o aprender e construir conhecimento: enquanto um processo necessariamente vinculado e sintonizado com outros; enquanto uma empreitada de riscos que leva em conta, como estratégia de sobrevivência, as recalcitrâncias em humanos e não humanos; que oferece ocasiões para diferir num movimento em que todos os envolvidos se modificam pelos efeitos que causam reciprocamente uns nos outros; enquanto uma prática plural e inclusiva, tendo, finalmente, um mundo comum como o objetivo maior destas construções.
\end{abstract}

Palavras-chave: aprendizagens; teoria ator-rede; psicologia.

1 Graduada em Psicologia pela Universidade Federal do Rio de Janeiro(UFRJ) . Mestrado em Educação pela Pontifícia Universidade Católica do Rio de Janeiro (PUC/RJ). Doutorado em Psicologia Social pela Universidade Estadual do Rio de Janeiro (UERJ). Professora Adjunta do Departamento de Psicologia da Universidade Federal de São João del Rei. Membro do Laboratório de Pesquisa e Intervenção Psicossocial (LAPIP). Coordenadora da Brinquedoteca da Universidade Federal de São João Del Rei (UFSJ).Minas Gerais, Brasil. 


\begin{abstract}
In this paper, we pose learning as a dynamic and multifaceted phenomenon, which is the product of a series of conditions emerging from a networking causality, taking body as a mediating instance between subject and the world, affecting reciprocally each other. Based on concept of translation, defended by Actor-Network Theory, we searched their unfolding in Psychology field in order to understand the construction of identities as bets, always temporaries, of materiality and sociality processed mixtures, during human biography lifetime. We used Stengers-Despret principles, brought up to date for Latour, pointing to an alternative political epistemology reflecting on teaching, learning and knowledge construction: while a process is necessarily tied and tuned with others; while a risked enterprise that leads in account, as a survival strategy, human and on human recalcitrance; that offers occasions to differ in a movement where all the involved ones modify each others because of the produced effects; while a plural and inclusive practice, having, finally, a common world as the major objective of this constructions.
\end{abstract}

Keywords: learning; actor-network theory; psychology.

\title{
Introdução: algumas palavras sobre a Teoria Ator-Rede
}

A Teoria Ator-Rede (T.A.R.) nasceu no interior de um campo chamado Estudos da Ciência e Tecnologia e vem sendo trabalhada, desde os anos 80, com o compromisso de atender ao Princípio de Simetria instaurado pela Antropologia das Ciências. Consiste em manter, sob o mesmo arcabouço de análise, elementos humanos e não humanos, evitando toda a visão compartimentalizada da realidade. Em linhas gerais, a Teoria Ator-Rede defende a ideia de que, se os seres humanos estabelecem uma rede social, não é porque eles interagem apenas com outros seres humanos, mas é porque interagem com outros materiais também. A composição do que chamamos de social não se deve simplesmente a pessoas, mas igualmente a máquinas, animais, textos, dinheiro, arquiteturas, laboratórios, instituições... A TAR permite verificarmos uma multiplicidade de materiais heterogêneos conectados em forma de uma rede que tem múltiplas entradas, está sempre em movimento e aberta a novos elementos que podem se associar de forma inédita e inesperada. Definida como um método, mais do que como uma teoria, funciona sob a lógica das traduções que operam aproximações e efetuam passagens (SERRES, 1999). Nas redes, vale o princípio da conecti- 
vidade, do que pode ser aproximado, conectado, modificado pelo encontro de instâncias que buscam traduzir as diferenças pelos deslocamentos efetuados, sejam estes geográficos ou linguísticos, num espaço de fronteiras. Concebida a partir de múltiplas influências, traz a marca da interdisciplinaridade quando segue os rumos que tomam os fenômenos, entendidos como efeitos dessas redes que mesclam simetricamente pessoas e objetos, dados da natureza e dados da sociedade, oferecendo-lhes igual tratamento. O fato científico passa a ser compreendido como a expressão de uma rede que tem seus efeitos em escala.

Em Jamais fomos modernos, Latour (1994) entende que aqueles que se julgaram modernos, na ânsia de desbancar as antigas verdades, funcionaram sob a lógica da exclusão, pois, ao introduzirem novas ideias, promoveram a ruptura e o apagamento daquelas que representavam o pensamento anterior, tido como obsoleto, instaurando um novo regime de pensamento em que se opera uma dupla ruptura: no tempo, por oposição a uma antiguidade supostamente arcaica; e entre grupos de vencedores e de vencidos, nas guerras das ideias pela supremacia de uma suposta "verdade" dos fatos. Com estas premissas, muitas outras cisões foram instaladas, ficando toda a lógica de pensar as ciências viciada por essa necessidade de purificação através da divisão. Trata-se de uma visão que congela, em grande medida, a possibilidade de transformação nas pontas, sem levar em conta que estas estão em contínua mistura, produzindo híbridos incessantemente e indefinidamente. Ao invés da imposição de uma(s) parte(s) sobre outra(s), da substituição de uma(s) pela outra(s), como pretendeu o projeto moderno, as partes se transformam no contato com versões heterogêneas, reunindo propriedades através do ajuste de práticas e interesses híbridos, meio pelo qual estas partes recebem, umas das outras, a chance de transformação mútua (DESPRET, 2002).

Com o fenômeno da aprendizagem, não aconteceria diferente. Dada a sua complexidade, ele emerge como resultante de uma série de vetores que vão se combinando de maneira complexa, ao longo da biografia dos seres vivos, nas interações feitas com as entidades do contexto em que vivem, respondendo aos inúmeros desafios que a sobrevivência lhes impõe. O que estamos aqui chamando de entidade é definido por Latour (2002) como tudo o que existe ou pode existir, produzindo ou sofrendo efeitos pela ação de outras. Neste interjogo de forças, as estratégias de existência implicam em levar em conta as recalcitrâncias ${ }^{2}$ de elementos humanos e não humanos estes últimos tomados como parte dos coletivos compostos conjuntamente com os humanos, tendo a potencialidade de

2 Recalcitrância é qualidade dos actantes cujas manifestações não são facilmente controladas, resistindo às tentativas de domesticação por parte de outros actantes. Para um estudo sobre a recalcitrância, ver mais em Tsallis (2005). 
se revelarem actantes, ou seja, de exercerem ou sofrerem algum tipo de ação, participando de um processo. Os não humanos são tudo que, não sendo humano, joga a favor da construção da nossa humanidade.

\section{Aprender: traduzir e deixar-se afetar}

Uma análise etimológica das palavras ensinar e aprender pode nos ajudar a defender o raciocínio que se seguirá.

Ensinar - do latim insignare quer dizer colocar uma insígnia, um sinal; assinalar, fazer insigne, memorável (CRETELLA Jr.; CINTRA, 1953). Acrescentamos aqui tornar diferente, diferenciar.

Aprender - do latim apprehendere quer dizer apreender, pegar, prender, conquistar (CRETELLA Jr.; CINTRA, 1953). Acrescentamos aqui guardar, reter, ter como parte de si, incorporar.

A aprendizagem, como uma incorporação de saberes e fazeres, só faz sentido se a pessoa dispõe dela para operar efeitos sobre si e sobre o mundo. Essa possibilidade de lançar mão de determinados conhecimentos torna-se possível, uma vez que o aprendido faça sentido e seja digerido/transformado como parte daquele que aprende, ou seja, desde que se opere uma "tradução", desde que se ache um nexo entre o que se pretende ensinar e o que se pode aprender de um assunto num determinado momento. Caso contrário, acreditamos que a aprendizagem de fato não se processa, podendo meramente ocorrer o que Jorge Visca (1987) chama de aprendizagem mimética, ou seja, aquela que ocorre por uma pressão circunstancial - como na urgência de uma prova - mas logo se perde porque resta como corpo estranho, sem fazer sentido na vida daquele que supunha ter aprendido. Para sermos fiéis a Teoria Ator-Rede, na abordagem das aprendizagens, entendemos que cada sujeito tem suas aprendizagens ligadas a uma rede que lhes dá sustentação e que se origina em vários coletivos ${ }^{3}$. Uma aprendizagem desconectada não se sustenta enquanto uma bagagem vivencial que possa vir a ser utilizada: aquele que está numa posição passiva de apenas receber o conhecimento pronto e "enlatado" fica impedido de realizar a sua tradução e de acrescentar a sua marca. $\mathrm{O}$ conhecimento estará irremediavelmente solto e sem sentido, sendo tão mais perecível quanto menos requerido for.

Se tomarmos a palavra traduzir com o significado de tornar uma linguagem compreensível, transformar um enunciado problemático numa linguagem de um outro enunciado particular, poderíamos, então, entender a aprendizagem como

3 Coletivo entendido aqui como uma associação entre humanos e não humanos. 
uma ação que traduz e que transforma: na transmissão de um saber ou uma práti$\mathrm{ca}$, tanto aquele que ensina como aquele que aprende precisam encontrar pontos de passagem para tornar a tradução $0^{4}$ possível, para tornar o aprendido parte de si, imprimindo nele a sua marca. Latour (2001) toma a palavra translation a partir de seu duplo sentido, tanto podendo significar o deslocamento de uma linguagem à outra, como de um lugar a outro. Em ambos os casos, entendemos que o processo de tradução se aplica às aprendizagens, pois, para aprender, precisamos necessariamente realizar essas passagens linguísticas e geográficas, operando, sobre a cadeia de mediadores, movimentos que, ao mesmo tempo, conservam e deformam os registros em questão. Para aprender, precisamos viver a aventura de abandonar as referências, assim como precisamos nos defrontar com a possibilidade de decifrar códigos desconhecidos, nos efeitos provocados no âmbito dos coletivos.

Além da noção de tradução, interessa-nos utilizar a ideia de que, para aprender, precisamos da materialidade de um corpo que se afeta, que é colocado em ação por outras entidades (humanas e não humanas), tornando-se sensível ao que está ao seu redor. Em How to talk about the body (2002), Latour tenta escapar da definição de corpo tomado como uma substância, entendido como uma "residência provisória de algo superior - uma alma imortal, o universal, ou pensamento - mas o que deixa uma trajetória dinâmica pela qual nós aprendemos a registrar e nos tornar sensíveis àquilo de que é feito o mundo"5 (p. 1). No modelo com que estamos acostumados a trabalhar, assentado nas rupturas instaladas pelo pensamento moderno, de um lado há o corpo dentro do qual está o sujeito, como uma essência, e lá fora está o mundo povoado de objetos, havendo intermediários - a linguagem - para estabelecer as conexões entre ambos. A aprendizagem, numa perspectiva moderna, cumpre a função de apurar um sujeito que já está lá, mas não é fundamental para dar-lhe a condição de alguém que possa afetar e ser afetado pelos outros, uma vez que apenas duplica um conhecimento que vem de fora, reforçando a dicotomia sujeito conhecedor $\mathrm{x}$ objeto a ser conhecido.

Se pretendemos passar ao largo dessas dicotomias, entendemos que nem sujeito nem mundo são dados a priori, estando ambos em permanente construção: o sujeito é modificado/afetado quando aprende e o mundo também não será o mesmo depois da aprendizagem, pois terá sofrido uma tradução por aquele que

4 Ao invés da palavra transmissão, que pode pressupor a passagem de informação sem deformação, entendemos que será melhor usar a ideia de tradução adotada em nosso estudo.

5 A tradução é de nossa responsabilidade. 
aprendeu. A ideia de corpo como uma instância mediadora ${ }^{6}$ das aprendizagens leva em conta a materialidade dos humanos e dos não humanos num espaço de trocas para a produção de qualquer fenômeno da realidade. Esta materialidade das entidades está longe de ser inócua, uma vez que ela mesma é vetor de transformações, ao mesmo tempo em que é passível de ser transformada. Os humanos nunca estiveram no mundo sem intercambiar propriedades com os não humanos, sem se deixar afetar por eles. A ideia de ser um entre outros, de afetar e de deixar-se afetar pelo que está ao redor, dá uma conotação política à questão das aprendizagens, implicando num compromisso de articulação do sujeito e seu mundo. A lógica das conexões vale igualmente para os sujeitos e suas fabricações: para ser interessante e ter valor é preciso estar articulado, afetado por entidades cujas diferenças vão ser incorporadas de maneiras novas e inesperadas. Nas palavras de Latour (2002, p. 3),

Um sujeito desarticulado é alguém que, não importa o que os outros digam ou façam, sempre sente, age e fala a mesma coisa. [...] Por oposição, um sujeito articulado é alguém que aprende a ser afetado pelos outros - não por si próprio.

As articulações, para o autor, oferecem mais chances de produzir objetos novos do que o modelo de ciência vigente que busca a exatidão da réplica e, portanto, cai na tautologia. As articulações são muito mais férteis na produção de diferenciações e, assim, muito mais ricas.

Para Latour (2002, p. 3), quando um indivíduo aprende, ele se deixa afetar e se torna cada vez mais diferenciado porque terá estabelecido mais e mais conexões, tornando-se mais interessante e enriquecido na relação com o seu entorno (uma rede de elementos variados e heterogêneos do qual ele também é parte). Se o conhecimento é concebido como o resultado de uma articulação e a aprendizagem como uma forma de se deixar afetar, de se deixar tocar em toda a materialidade do corpo, então poderíamos questionar as bases em que as aprendizagens são propostas, quando assentadas numa visão que separa o corpo do mundo e trabalha a transmissão de conhecimento como uma cópia a ser imitada.

6 É importante trazer a distinção entre um intermediário e um mediador. Para Latour (2002c), um intermediário é aquele que veicula sentido ou força sem provocar transformação, ou seja, definir seus imputs é suficiente para saber seus outputs. Para um mediador, não basta conhecer seus imputs para predizer quais serão os seus efeitos, pois é preciso levar em conta, a cada vez, a sua especificidade. Os mediadores não transportam simplesmente os elementos: eles transformam, traduzem, distorcem e modificam os elementos que transportam e não são, portanto, inócuos. 


\section{Princípios para pensar numa aprendizagem articulada}

Latour (op. cit.) utiliza oito pontos para discutir o significado do que vem a ser científico, numa epistemologia política alternativa, valendo-se das ideias defendidas por Isabelle Stengers e Vinciane Despret ${ }^{7}$, em seus trabalhos. São estes mesmos pontos que tentaremos aqui tomar como base para pensar a fabricação do conhecimento e a sua passagem às novas gerações, tentando operar a nossa tradução no que entendemos que possa ser uma situação de ensino-aprendizagem não moderna. Estes princípios nos dão a oportunidade de fazer algumas reflexões úteis para uma Psicologia Ator-Rede.

1. Não há uma metodologia única para construir conhecimento, muito menos para ensinar e aprender. Cada pessoa, a partir de sua história e das redes que a compõem, terá um estilo único de realizar esta tarefa que estará sempre passível de modificações em função das novas conexões que forem ocorrendo, fato que a deixará tão mais diferenciada quanto mais vinculada estiver (ARENDT, 2004).

Pensar numa causalidade em redes nos deixa em melhores condições de entender como determinado ator, na mescla com outras entidades, pode produzir a si e ao mundo de maneira absolutamente singular e, ao mesmo tempo, intensamente vinculada. Ser um sujeito não é algo atribuível a uma suposta e prévia interioridade. Esta, diz Latour (2006), é construída de uma maneira complicada: para que "um corpo anódino e genérico seja transformado em pessoa [...], um fluxo de entidades lhe permite existir" (p. 305), pois, como todas as outras coisas, há um trabalho de fabricação de cada sujeito, idéia que o nosso autor toma claramente de empréstimo a Gabriel Tarde.

Existir é diferir, pois a diferença seria o lado verdadeiramente substancial das coisas, o que elas têm, ao mesmo tempo, de mais próprio e mais comum. [...] A identidade é apenas um mínimo, uma espécie infinitamente rara de diferença como o repouso não é mais que um caso do movimento, como o círculo é apenas uma variedade da elipse (TARDE apud LATOUR, 2006, p. 27).

7 Estas autoras, segundo Latour (2002), nos deixam uma lição quando oferecem "a pedra de toque para distinguir a boa da má ciência” (p. 11) Tradução nossa. 
Equivocadamente, segundo estes autores, partimos da identidade para entender o que as coisas são, mas é o que elas têm de comum que deveria ser o nosso ponto de partida. Como atores, podemos verificar o traçado que os vários grupos aos quais pertencemos foram deixando em nós: as marcas para fazer emergir aquilo que somos. Isto, entretanto, não quer dizer que estamos na mão única da determinação - e nem tampouco na via da autonomia, pois as entidades que se cruzam para a emergência dos atores funcionam numa causalidade em redes que dispensa a sociedade e a natureza como únicas matrizes produtoras de efeitos naquilo a que chamam de exterioridade. Há outros elementos subjetivadores, personalizadores ou individualizadores que, em fluxo e de forma mais sutil, permitem transformarmo-nos em indivíduos e conquistar uma interioridade. Também chamados de plug-ins $^{8}$, esses recursos vão nos possibilitando acessar cada vez mais conexões que nos subjetivam, ampliando o nosso acesso ao mundo. Pela multiplicação de nossas conexões com a realidade, recorrendo a um grande número de subjetivadores, constituímos, portanto, nossa interioridade e, assim, quanto mais conectados, mais subjetivados estaremos. Tomando o exemplo tão caro a Latour em vários dos seus textos $(2002,2006)$, utilizamos a ligação entre os marionetistas e suas marionetes: na relação entre estas duas pontas, algo se passa ao longo dos fios que permite às marionetes se mexerem. É na passagem, no espaço entre, que as traduções acontecem, numa relação mais sutil que aquela meramente de causa e efeito. Ao contrário de pensar que, para ser livre, um sujeito deve estar liberado das conexões que o mantém, a Teoria Ator-Rede postula a ideia de que alguém desvinculado revela uma situação de empobrecimento. Uma marionete sem fios não se move; com poucos fios tem movimentos limitados; com muitos fios, promove-se uma sofisticação crescente de sua performance. Tudo vai depender da relação que se estabelece entre marionetista e marionete.

2. Para ser ensinado/aprendido, o conhecimento precisa ser interessante; e ser interessante é necessariamente ser articulado, estar sintonizado com o outro, fazer eco nos projetos de vida e nas motivações do outro. Ser simplesmente exato não dá a garantia de um conhecimento interessante. Além de exato, como pretendem ser as verdades científicas, ele pode ser igualmente enfadonho, redundante e, portanto, estéril, porque mal articulado.

8 Figura tomada da informática que, na proposta de Latour (2006), significa aquilo que nos deixa acessar, visualizar, fazer conexões com quadros que fazem crescer as nossas possibilidades de ação. 
Falar sobre as aprendizagens na contemporaneidade implica em voltar o nosso olhar para as situações de alta velocidade com que as informações se difundem e se democratizam, convivendo, simultaneamente, com práticas educacionais que veiculam conteúdos pedagógicos em sua grande maioria apartados de uma realidade vivenciada por aqueles cuja apatia diante do aparato escolar pode ser apontado como um sintoma já reiteradamente denunciado.

3. Ensinar/aprender/conhecer é uma empreitada de riscos. Posições préestabelecidas na assimetria devem ser colocadas à prova. $\mathrm{O}$ risco pode ser o abandono do privilégio de estar no comando (de quem detém a verdade, de quem sabe), como pode ser abdicar das certezas de um conhecimento que já perdeu sua validade, em prol de um outro, desconhecido, que, por esta condição, é ameaçador.

O processo de ensinar/aprender como uma empreitada de riscos e não como uma evitação de erros passa a fazer toda a diferença nas maneiras como cada sujeito vai se posicionar diante do mundo. Se não nos arriscamos, não tem aprendizagem. Também não há vida, se nos poupamos de viver o caos e o risco que são motivadores de novas oportunidades. Por isso é importante tomar a aprendizagem como uma oportunidade de viver e elaborar situações que nos provocam grande impressão.

4. Olhar para as recalcitrâncias em humanos e não humanos é uma estratégia de sobrevivência. Aprender/ensinar tem muito a ver com esse olhar, com esta atenção àquilo que resiste, porque são essas recalcitrâncias que podem nos propiciar uma reorientação de estratégias na busca por melhores efeitos. As formas de recalcitrar podem variar muito de humano para humano e de não humano para não humano, mas sempre poderão ensejar muitas e valiosas aprendizagens para todas as partes envolvidas.

As recalcitrâncias, sejam oriundas de humanos ou de não humanos, são poderosos indicadores de uma indisponibilidade para realizar negociações por parte de pelo menos um dos segmentos envolvidos, impedindo que uma possível troca de propriedades configure novas versões sobre o que estava dado à princípio. Por outro lado, estas formas de resistir a uma negociação com uma outra entidade podem promover oportunidades para desenvolver novas estratégias de entrar em contato e de lidar com o que antes não conhecíamos muito bem. Aprender significa estarmos disponíveis para realizar uma boa quantidade de traduções empreendidas a partir das relações que estabelecemos com elemen- 
tos variados, nesta empreitada em que humanos e não humanos não são meros intermediários, mas ativos mediadores.

5. Oferecer ocasiões de diferir é outro ponto fundamental. Para tanto, torna-se imprescindível deixar falar o que até então estava mudo, permitindo a interferência do interesse, da dúvida ou da discordância. Para que haja aprendizagem, a articulação entre quem ensina, quem aprende e o conteúdo aprendido deve ser interessante, afetando e modificando a todos.

Quando temos o ensinar e o aprender não mais como duas ações que se processam em dois corpos separados através de papéis pré-estabelecidos, mas como algo que se constrói num espaço entre onde a inter-ação acontece, interessando e modificando a todos, as interferências e as discordâncias não são mais vistas como um efeito a ser evitado: diferir passa a ser vital como produto das negociações estabelecidas por quem ensina/aprende. ${ }^{9}$

6. Nem distância, nem empatia definem uma boa aprendizagem/um bom conhecimento/ uma ciência bem articulada. A distância e a empatia, nas aprendizagens não modernas, parecem ser uma questão de foco e de ângulo: muito perto e muito longe, muito envolvimento ou indiferença dificultam a abordagem do objeto novo.

Estar muito/pouco envolvido, muito perto ou muito longe, é uma condição que pode fazer falhar aquele que ensina/aprende, aquele que pesquisa ou aquele que faz ciência porque ele não pode esquecer a sua tarefa, nem a chance de se diferenciar junto com aquilo que pesquisa. A empatia se refere aos possíveis vieses, paixões e preconceitos que interferem nas situações em questão. Eles não só podem aparecer como devem ser colocados à prova. Quanto à distância, não se trata, segundo Latour, somente daquela entre dois pólos contemporâneos (observador/observado; quem ensina/quem aprende...), mas entre os conteúdos do mundo antes e depois do fenômeno. Se há uma distância entre o novo repertório de ações do pesquisador, do cientista, da entidade aprendensinante ${ }^{10}$ e aquele que foi ponto de partida, então nada foi em vão: todas as partes se

9 Em algumas línguas como o francês, por exemplo, temos uma só palavra - apprendre para o ensinar e o aprender.

10 Termo cunhado por Fernandes (2001). Muito antes, Vygotsky já havia cunhado em russo o termo obuchenie que teria como tradução algo análogo à "ensinagem", demonstrando a indissociabilidade do ensino/ aprendizagem. Ver Oliveira (1993, p. 57) 
diferenciaram, tornaram-se mais vinculadas e mais interessantes. A empatia e a distância só serão úteis se ajudarem a maximizar as ocasiões para que o fenômeno investigado ofereça outras questões para além das questões iniciais levantadas pelo investigador.

7. Como efeitos da prática científica, da fabricação do conhecimento, de um processo de ensino/aprendizagem, podem surgir generalizações boas e más.

Tanto melhores serão as generalizações quanto mais conexões ocorrerem entre variados fenômenos, gerando o reconhecimento da maior quantidade de diferenças, "por engajar o destino de umas poucas entidades na vida e no destino de muitas outras" (LATOUR, 2002, p. 9). Ao contrário, as generalizações más são aquelas que tiveram a pretensão de serem tomadas como verdadeiras e de se assumirem como universais porque, num determinado tempo e lugar, obtiveram sucesso. As boas generalizações se legitimam pela extensão da rede em que circulam e pelos efeitos que produzem, não pela imposição de alguns poucos quando estes entendem que as diferenças são irrelevantes.

8. Permitir um mundo comum deve ser o destino de uma epistemologia política, da fabricação de fatos científicos, de qualquer processo ensino/aprendizagem. Não é possível conquistar um mundo para todos, se o ponto de partida já foi estabelecido previamente, longe dos olhares dos interessados. Articulações poderão ser avaliadas como boas (ou más), na política ou na ciência, quanto mais inclusivas forem, quanto mais diferenciações permitirem, quanto mais falantes deixarem os nós da rede.

Como compor "um mundo plural, mas comum" é o assunto de um dos livros de Bruno Latour (2005) e penso que é a questão onde se localiza todo o esforço de construção da sua Epistemologia Política. Se um mundo comum não pode ser dado por antecipação por alguns poucos em detrimento daqueles que chegam a seguir candidatando-se à sua composição, penso que precisamos nos posicionar na busca por outras soluções. Essa divisão traçada entre os que já se encontram e outros que aparecem posteriormente é praticamente o mote para a maior parte dos conflitos que encontramos no mundo, seja entre ideias no âmbito pessoal ou no âmbito científico, seja entre grupos que disputam por recursos ou poder. Qualquer facção que se declara em guerra em relação à outra, reivindica para si o privilégio da verdade ou da primazia sobre algo que funciona como o pivô da contenda. Os pensadores modernos produziram um 
processo de separação que resultou na clivagem de várias instâncias, na forma como os sujeitos passaram a entender a realidade: fatos $\mathrm{x}$ fetiches, crença ingênua $\mathrm{x}$ ciência, sujeito $\mathrm{x}$ objeto, natureza $\mathrm{x}$ cultura, teoria $\mathrm{x}$ prática, coisa $\mathrm{x}$ representação, interioridade $\mathrm{x}$ exterioridade, ciências da natureza $\mathrm{x}$ ciências humanas, agravando e legitimando esta tendência ao conflito, especialmente no olhar que as ciências lançaram sobre grupos que não fossem os legisladores das próprias causas, em detrimento das causas defendidas por outros (de culturas diferentes, de outras gerações, de outras crenças, de outros valores). Assim, todas as teorias com apelos ao universal se encontram passíveis de conter em si o germe do enquadramento e da discriminação do diferente, daquilo que não é o seu espelho. $\mathrm{O}$ esforço de simetria, que está longe de ser confundido com uma postura de neutralidade, poderia oferecer uma oportunidade para a composição deste mundo comum.

O encontro com o que é diferente não deveria, então, pressupor um jogo de trocas em que, através do conhecimento mútuo, pudéssemos incorporar as características do outro, sem necessariamente copiá-lo, numa ação de submetimento? A recíproca não deveria ser também verdadeira? Em todas as ocasiões em que pessoas ou povos de diferentes culturas entram em contato, pacificamente ou beligerantemente, há um saldo de práticas e costumes que se interpenetram e ficam como marcas deste encontro em ambas as partes (QUEIROZ E MELO, 2007, p. 181)

Vemos as aprendizagens, entre outros fenômenos que ocorrem nas interações, como um exercício da capacidade (que uns adquiriram e outros não) de se colocarem no lugar do outro, dando ao outro lugar para se colocar; de estudar as estratégias do outro para enriquecer as suas próprias; de ensaiar, de errar, de acertar; de constituir algo que acontece entre duas entidades diferentes que se encontram e testam suas forças, buscando por um certo equilíbrio, ainda que provisório, na constituição de si e do mundo.Tornar falantes os nós da rede, deixando aparecer o que estava à margem, permitindo o posicionamento daqueles que não podiam até então aparecer, é parte deste exercício de convivência com o diferente. Realçar as diferenças quando a tendência for homogeneizar, torná-las planas quando a tendência for discriminar talvez seja uma boa estratégia nesse exercício de compor um mundo plural e comum. 


\section{REFERÊNCIAS}

ARENDT, R. Psychology and the Actor-Network Theory. Paper presented in the $4 S$ \& EASST Meeting, École des Mines de Paris, 2004.

CRETELlA JR, J.; CINTRA, G. U. Dicionário Latino-Português. 3. ed. São Paulo: Companhia Editora Nacional, 1953.

DESPRET, V. Quand le loup habitera avec l'agneau. Paris: Les empecheurs de penser em rond, 2002.

FERNÁNDEZ, A. O saber em jogo. A psicopedagogia propiciando autorias de pensamento. Porto Alegre: Artmed Editora, 2001.

LATOUR, B. Jamais fomos modernos. Rio de Janeiro: Editora 34, 1994a.

. A esperança de Pandora. Bauru, SP: EDUSC, 2001.

. Reflexão sobre o culto moderno dos deuses fe(i)tiches. Bauru, SP: EDUSC, $2002 \mathrm{a}$.

. The Promises of Construtivism. Disponível em: <www.ensmp.fr/ latour>. Artigos on line de Bruno Latour, 2002b.

. How to talk about the body? The normative dimension of sciences study. Disponível em: <www.ensmp.fr/ latour>. Artigos on line de Bruno Latour, 2002c.

.Um monde pluriel mais comum. Entretiens avec François Ewald. Paris: Éditions de l'Aube, 2005.

. Changer de societé. Refaire de la sociologie. Paris: La Découverte, 2006.

QUEIROZ E MELO, M. F. A. Voando com a pipa: esboço para uma Psicologia Social do Brinquedo à luz das idéias de Bruno Latour. Tese (Doutorado) - Programa de Pós graduação em Psicologia Social da UERJ, 2007.

OLIVEIRA, M. K. Vygotsky, aprendizagem e desenvolvimento em processo sociohistórico. São Paulo: Editora Scipione, 1993.

SERRES, M. Luzes. Cinco entrevistas com Bruno Latour. São Paulo: Unimarco Editora, 1999.

TSALLIS, A. C. Entre terapeutas e palhaços: a recalcitrância em ação. Tese (Doutorado em Psicologia Social) - Rio de Janeiro: Universidade do Estado do Rio de Janeiro, 2005. 
MELO, M. F. A. Q. Discutindo a aprendizagem sob a perspectiva da teoria ator-rede

VISCA, J. A clínica psicopedagógica. Epistemologia convergente. Porto Alegre: Artes Médicas, 1987.

Texto recebido em 14 de junho de 2009

Texto aprovado em 02 de novembro de 2009 